\title{
LOS SONIDOS AGRÍCOLAS DEL PASADO VASCO EN EL ENTORNO URBANO
}

\author{
Arantza Gaztañaga Garabieta \\ Universidad del País Vasco / Euskal Herriko Unibertsitatea. Dpto. Escultura y Arte y Tecnología. \\ Doctoranda
}

\section{Resumen}

En este artículo queremos exponer una práctica artística y experimental de arte participativo, realizada entre los años 2016 y 2018, en el que se presentaba un objeto tradicional llamado txalaparta en relación con un espacio. Dos puestas en escena, en dos sitios diferentes de un mismo objeto, uno de ellos en donde el instrumento es conocido, mientras que en el otro no. Dentro de esos espacios, la artista y espectador crean un vínculo en el que la visualización de una nueva adaptación sistemática de este objeto trasladado al soporte cerámico se conjuga en el entorno urbano, llamando así la atención de la gente y haciéndoles partícipes de un proceso de recepción estética, conformando círculos relacionales en el que la artista se posiciona en lugar del espectador y viceversa. Interpretamos aquellos sonidos del pasado vasco como una experiencia musical urbana, que se convierte en fundamental y a la vez dinámica, en la que la perspectiva y actitud social de la gente cambia por las diferencias culturales.

\section{Palabras clave: ARTE SONORO; TXALAPARTA; PARTICIPATIVO; INSTA- LACIÓN; CERÁMICA}

\section{BASQUE ANCIENT FARMING SOUNDS INTO AN URBAN ENVIRONMENT}

\section{Abstract}

This paper wants to show an experimental participative artistic practice which was done between 2016 and 2018 where a traditional object called txalaparta was shown in relation to a particular space. Two stagings involving the same object in different locations. In one of them, the object is well known whereas in the other, remains unknown. Inside those spaces, a link is created between the artist and the spectator, where the visualization of a systematic adaptation of the object, which is changed to a ceramic material, combines with the urban environment. The attention of any spectator is taken becoming them participants of a process of aesthetic reception inside relation circles where artist's place is swapped with the position of the audience. Those ancient Basque sounds are interpreted as an urban musical experience which is transformed in fundamental and dynamic, generating changes in the attitude of people from different places and cultural contrast.

\section{Key words: SOUND ART; TXALAPARTA; PARTICIPATIVE; INSTALLATION; CERAMICS}

\footnotetext{
Gaztañaga GarabietaArantza. 2021. "Los sonidos agrícolas del pasado vasco en el entorno urbano". AusArt 9 (1): 55-68. D0I: 10.1387/aus$\operatorname{art.} 22576$
}

\section{AUSART}




\section{INTRODUCCIÓN: MEDIDAS DE ACTUACIÓN TEÓRICADE UN ARTISTA PLÁSTICO}

En la propia esencia antropológica del País Vasco a través de la música, está contemplar escenarios muy diversos relacionados con el mundo agrícola e industrial, en los que este territorio ha llevado al propio terreno de la sonoridad y los ritos suburbanos en el pasado. Entender aquellas sonoridades ancestrales, conlleva en sí mismo la trasformación y desarrollo de nuevos mecanismos en el arte contemporáneo que trasladen al espectador a esa esencia tan arraigada, está en la mente vasca. Suele ser en gran medida bastante complejo transformar esa perspectiva en proyectos artísticos que modifiquen el pasado histórico, lo que provoca, a la vez un rechazo y desinterés cultural por algunos espectadores. La razón de esta cierta resistencia podría ser que el contenido de muchas de las obras no se explica por sí mismo.

El acercamiento que se puede tener al arte suele ser principalmente a través de organismos institucionales como museos o privados como galerías, que en cierto modo no permiten que el arte pueda ser tocado o sentido de otras formas que no sea a través de estimular otros sentidos o percepciones a parte de lo visual, simplemente por el hecho de que las obras de arte deben ser conservadas a largo plazo. Rosalind Krauss señalaba que el modelo de observación inerte había dejado sitio a un modo de interacción basado en una serie de prácticas que tienen su origen en unas lógicas culturales preestablecidas (Krauss 1979)

Bajo esta premisa, para este proyecto he elaborado una serie de objetos musicales que reinterpretan la visión del instrumento tradicional vasco llamado txalaparta. Estos instrumentos se han desarrollado a través de distintos materiales cerámicos que dotan al objeto en cuestión de un interés creativo e interactivo a través de su reinterpretación y que aluden directamente a los elementos culturales preexistentes que hemos mencionado.

Haciendo uso de dichas txalapartas he creado una instalación, con la que el público puede interactuar obteniendo una experiencia sonora y lúdica. De esta manera, aporto una visión actualizada de este instrumento divulgando la txalaparta y expandiendo su conocimiento.

Finalmente, trasladando estas obras al entorno urbano, he experimentado junto al público las diferentes variantes en cuanto a su reinterpretación, dando 
a lugar distintos comportamientos en la interacción con la misma, iterándola sobre todo en un ambiente distendido y totalmente social.

\section{EL PORQUÉ DE LA TXALAPARTA}

En torno a 1965, surgieron prácticas performativas en distintos movimientos con la idea de llevar el arte a las calles, fuera de museos, donde los artistas se situaban como observadores y participantes directos de las actividades. En esta época, las prácticas conceptuales y del arte de acción, propiciaban nuevas formas de pensar sobre la concepción de la obra, generando movimientos para el cambio social y evolucionando hacia ámbitos institucionales y educativos en los años posteriores. Podemos observar cómo artistas tales como Kaprow, Adrian Piper o Mierle Laderman Ukeles, con sus happenings y performances, buscaban una relación más cercana con el espectador, estableciendo la interacción y participación mediante la provocación y la improvisación.

Viendo la gran variedad de artistas que hicieron uso de las prácticas performativas, analicé a nivel personal que el comportamiento ritual de muchas tradiciones vascas tenía en cierto modo una relación con estas prácticas que coincide con un instrumento que ayudaba a entender esta idea, que era la txalaparta. La txalaparta es un objeto procedente de las labores agrícolas del País Vasco. En un principio no se puede asegurar la procedencia de este instrumento tan inusual, pero se especula que su relación viniera del proceso de trituración de la manzana para hacer la sidra (Ugarte. 2006).

Entre esas actividades podemos encontrar la manera en que se machacaba la manzana en el lagar para producir la sidra. Al aplastar la manzana con el pisón, los participantes lo golpeaban al mismo tiempo en grupos de dos o tres personas y de manera alterna. En todo ese golpeteo sucesivo se creaban unos juegos sonoros que intuían la presencia del ritmo. Los sonidos alternos producidos y escuchados durante el periodo de trabajo, se traducían una vez finalizados los mismos, posteriormente, en elementos festivos.

A través de la utilización de dichas herramientas de trabajo de manera lúdica y creando con los mismos diferentes frases rítmicas como divertimento, se convertía el ritmo de trabajo en juego y música, haciéndolo de esta manera 
mucho más llevadero. Al final de la elaboración de la sidra, por ejemplo, se hacía una fiesta para celebrar la apertura de las sidrerías, en donde personas de un mismo pueblo se reunían para probar la nueva cosecha, tocaban txalaparta y bailaban; es lo que los aldeanos vascos llamaban "Txalaparta Festa".

Estudiando el pasado de la txalaparta di con el investigador de la UPV/EHU, Argibel Euba, que en 2016 publicó el libro documental Basker, documentales suecos sobre la cultura vasca en la década de 1960 en el que se recopila gran parte de información y grabaciones acerca del modo de vida de los vascos en la década de los 60 . Viendo este documental, me di cuenta de que este objeto tenía un contenido histórico tan importante que trasmitía esa idea de arte comunitario de lógicas preestablecidas en función de elementos culturales arraigados, ya que el objeto era simplemente un juego de ritmos sonoros que se tocaba en colectivo a modo de ritual, y tal y como Argibel expresaba "La txalaparta tiene un toque demasiado simbólico".

Partiendo de este punto y fijándonos con detalle en la verdadera procedencia primitiva de este objeto de madera, queríamos trasladar e identificar la txalaparta en su propia historicidad; como es la cultura agrícola trasladándolo a un material que enfocase la idea de tocar la madre tierra o como diríamos en euskera Ama Lurra Jo. El material escogido para su construcción fue el barro, al que se podía dotar de otra sonoridad, más parecida a un material inorgánico como es la piedra. Desde mi posición como artista planteé este proyecto artístico titulado "Ttakun Zeramikoa. El golpe Cerámico", en el que se pretendió hacer una muestra de arte accesible, en la que la artista y espectador se conjugan en una misma acción performativa.

\section{DE LA CERÁMICA A LA AFINACIÓN}

Una vez concluida la construcción de este objeto tan particular, me percaté de que la investigación de la txalaparta en los últimos años había evolucionado de una manera insospechada, que muchos músicos vascos habían indagado en diferentes materiales como la piedra, la madera y el hielo para elaborar nuevas reinterpretaciones. Del mismo modo, estos artistas afinaban las piezas en escala de notas musicales para poder tocar una canción o ritmo musical; grupos como Kalakan, Txalamako Txalaparta taldea (Álava), HutsunTxalaparta 
(Navarra) y Oreka Tx (Gipuzkoa), los más importantes en la investigación de la txalaparta como instrumento musical.

Contacté con el txalapartari Mikel Ugarte de Oreka Tx, y compartimos ideas en cuanto a la txalaparta llegando a afinar la txalaparta cerámica, convirtiéndolo así no sólo en un objeto sonoro sino en un instrumento musical.
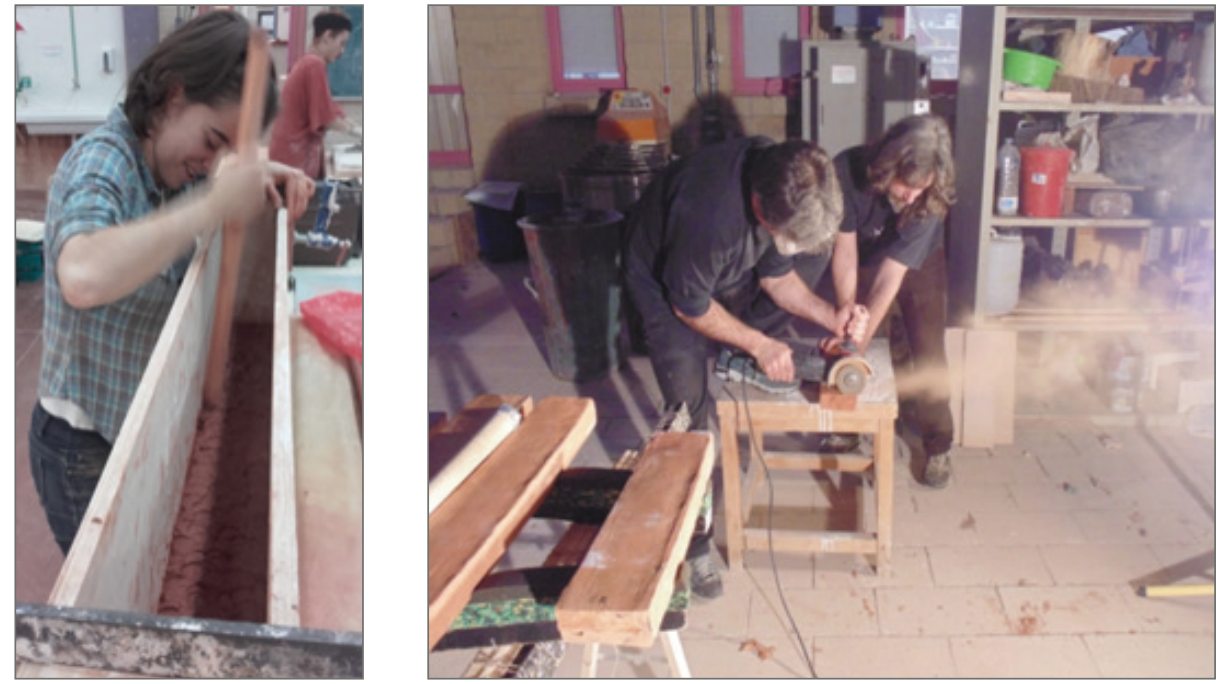

Observando los diferentes materiales utilizados, Mikel Ugarte comentó que en alguna ocasión ya había encontrado alguna txalaparta cerámica, pero realizada de forma precaria y hecha por baserritarras (campesinos), pero en este caso el modo de creación era mucho más elaborado. Concluyó diciendo que este instrumento debía terminar en un ambiente distendido y dándolo a conocer entre el público a modo de experimentación y como última tendencia de este instrumento tan particular procedente de la cultura vasca.

\section{DE LA CONSTRUCCIÓN A LAS CALLES SONORAS}

La colaboración con Mikel Ugarte finalizó dejando conclusiones que no esperaba desde un principio y que fortalecieron la idea de crear una obra participa- 
tiva, debía empezar a contemplar la construcción de un instrumento completo y tendría que buscar el modo de llevar esas piezas a la calle, en busca de esos sonidos urbanos.

No es fácil como artista buscar el momento y lugar idóneos para desarrollar un proyecto participativo, pero encontré distintas convocatorias artísticas en las que poder intervenir: por un lado, Bilbao Art District (2016) y más adelante Cohete Toledo (2018).

\section{BILBA0 ART DISTRICT}

Bilbao Art District se presenta todos los años como: una iniciativa público-privada cuyo objetivo principal es apoyar y poner en valor el sector de las artes visuales de Bilbao, convirtiendo la ciudad en un punto de encuentro de los diferentes agentes y disciplinas artísticas, así como acercando el arte a la ciudadanía. Teniendo en cuenta esto, creí oportuno coger las distintas versiones de la txalaparta creadas y llevarlas al ámbito suburbano para que la artista y espectador se relacionaran a través de este objeto a modo de interfaz.
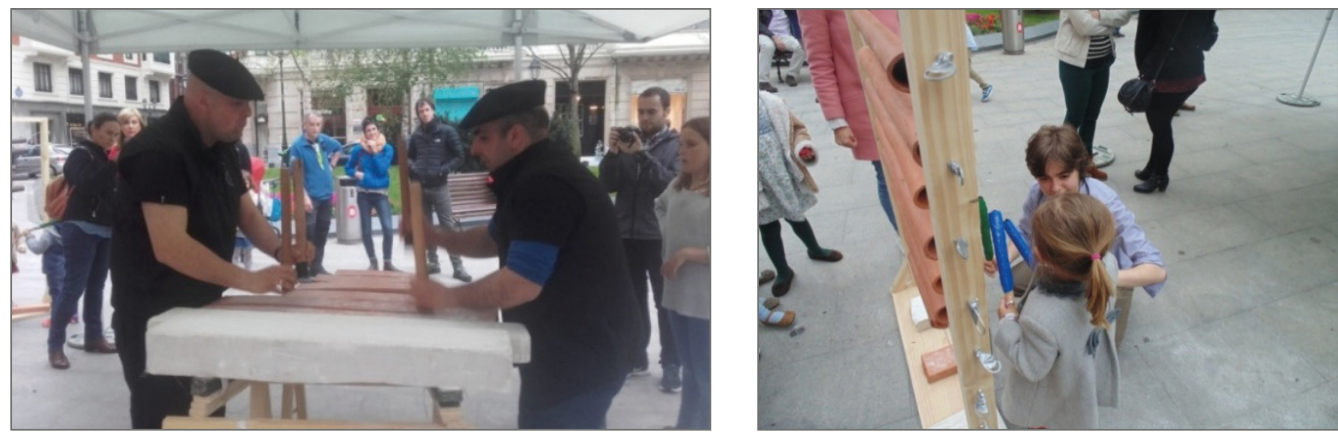

El arraigo cultural entre la txalaparta y los vascos es muy grande, y me figuré que podría dar mucho de sí. Pero la incógnita que surgía sobre este tipo de acción era cómo hacer que el espectador tomara parte en la performance que se iba a realizar, concretamente en la plaza Jado de Bilbao.

Las reflexiones de uno de los referentes en el arte público Siah Armanjani me sirvieron como reflexión inicial para dar sentido y elaborar una serie de inicia- 
tivas que me permitieran alcanzar el objetivo planteado. Armanjani afirmó que el arte público era un tipo de arte que no versaba sobre el artista ni sus necesidades, que tenía que ver con los demás, sus necesidades y, en definitiva, con crear un espacio en el que artista y ciudadanía intercambiaban posiciones. Armanjani decía también que para lograr estos fines se debía evitar a toda costa la intimidación y el control del público.
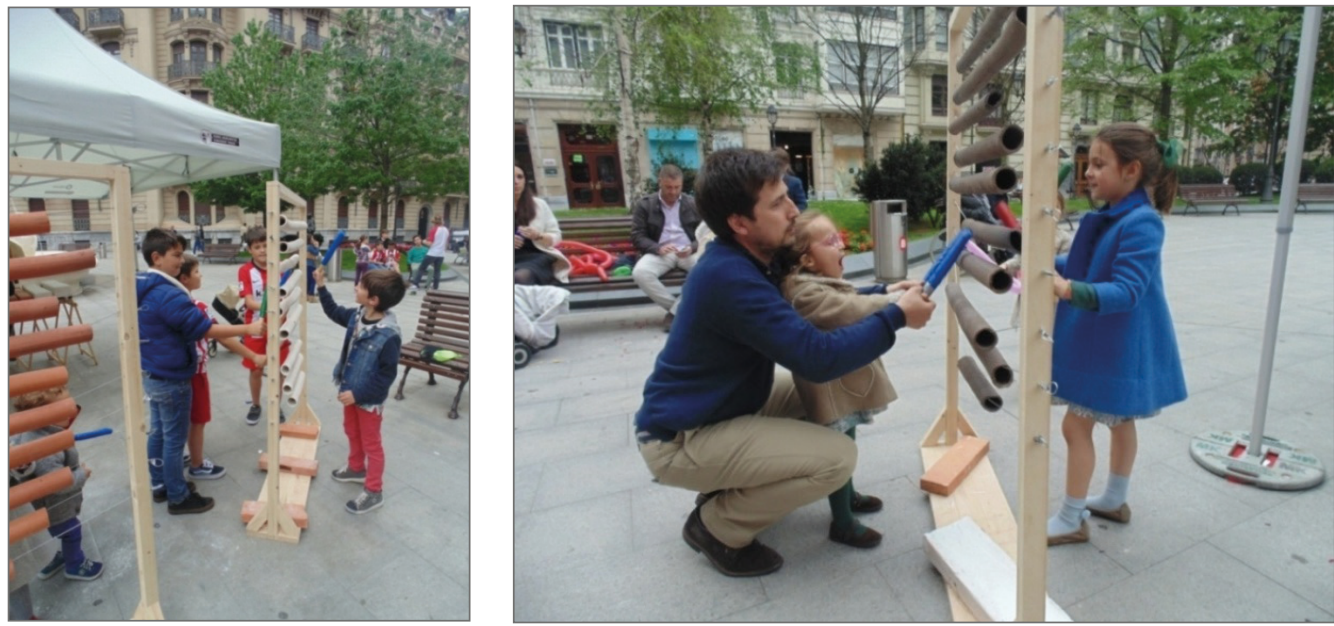

En un primer instante, supuse que la Txalaparta, un instrumento común y conocido en la cultura vasca, sería adecuado para lograr reducir la intimidación. Sin embargo, los elementos culturales arraigados y ya existentes, bajo mi punto de vista, fueron a la postre un obstáculo. Las personas que se acercaban mostraban a menudo reticencias para participar, sus propias expectativas sobre cómo debía sonar el instrumento y los ritmos parecían ser percepciones limitantes que restaban naturalidad a la participación. Cabe destacar, además, que estas limitaciones afectaban diferente en función de la edad, siendo las personas más participativas las de mayor y menor edad.

Para atraer al mayor número de viandantes, pensé también que sería adecuado contactar con diversos músicos, percusionistas y txalapartaris, cosa que logré tras realizar unas pocas llamadas. Los músicos eran procedentes de diferentes lugares de Euskadi, que habían participado en una gran parte de acciones artísticas o de protesta en cuanto a los intereses de la propia tierra vasca. Tuve la oportunidad de tener al grupo Txalamako Txalaparta Taldea, que es bien conocido entre los txalapartaris de Vitoria-Gasteiz. La performance callejera se desarrolló durante dos días y observé que existía una 
diferencia fundamental en la interacción con la performance entre las personas que conocían el instrumento de antemano y las que no.

Llevamos muchas variantes que reflejaban el carácter de la txalaparta, de materiales cerámicos como barro rojo, blanco y negro, además de la escayola. Añadiendo del mismo modo otro instrumento procedente del trabajo vasco, procedente de una cultura industrial llamado tobera, por lo que variaban en forma y carácter.

Las piezas fueron colocadas por toda la plaza a modo de instalación. Fue bastante sencillo tomar contacto con jóvenes entre edades comprendidas entre los 3 y los 12 años, se mostraron dispuestos a la participación desde el primer momento. Par la tarde, estos niños incitaban a sus familiares a participar. Eran realmente esos jóvenes los que creaban esa idea de acción performativa, que los vinculaba con esa tradición improvisada de los ritmos suburbanos del pasado al tiempo que conseguían ser elementos integradores entre diferentes grupos de edad.

Otro de los puntos a destacar fue la presencia de personas de diferentes culturas y razas que preguntaron en qué se fundamentaba el proyecto y hablaron sobre otros objetos similares en aspecto, como la marimba.
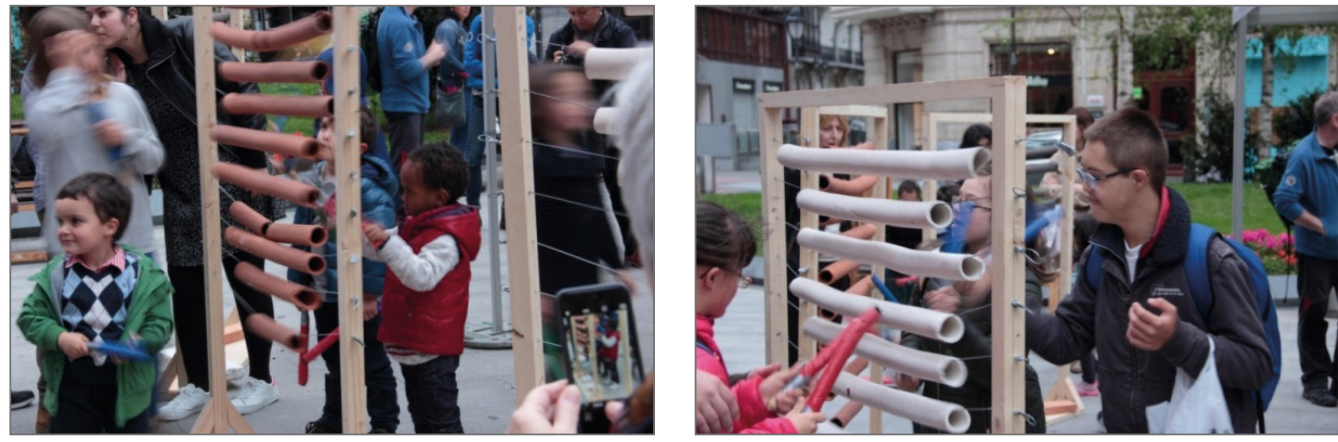

Fue este el punto en el que me percaté de que aun siendo ritmos procedentes de un bagaje histórico vasco, éste se trasladaba a tradiciones sonoras de otros lugares del planeta. La retroalimentación entre espectadores de diferentes procedencias y la artista fue muy pedagógica. Aun con sus diferencias se exploraba un cúmulo de sensaciones y a muchos de ellos, con ganas de participar, se les ofreció la posibilidad de experimentar y crear música formal. Algunos con mucha alegría dieron su propia versión sobre el objeto sonoro. 
Observé, por otra parte, que adolescentes y adultos -salvo alguna excepciónentre los 20 y 50 años, mostraban reticencias a la hora de participar, y es ahí cuando los txalapartaris entraban en acción junto con la artista, donde tocamos unas cuantas sesiones de txalaparta en las que, ofreciendo las makilas (los palos con los que se toca), se incluían dentro de la performance a aquellas personas poco activas en la práctica artística. Durante esas sesiones las personas observadoras de alrededor se convertían en artistas musicales por un momento.
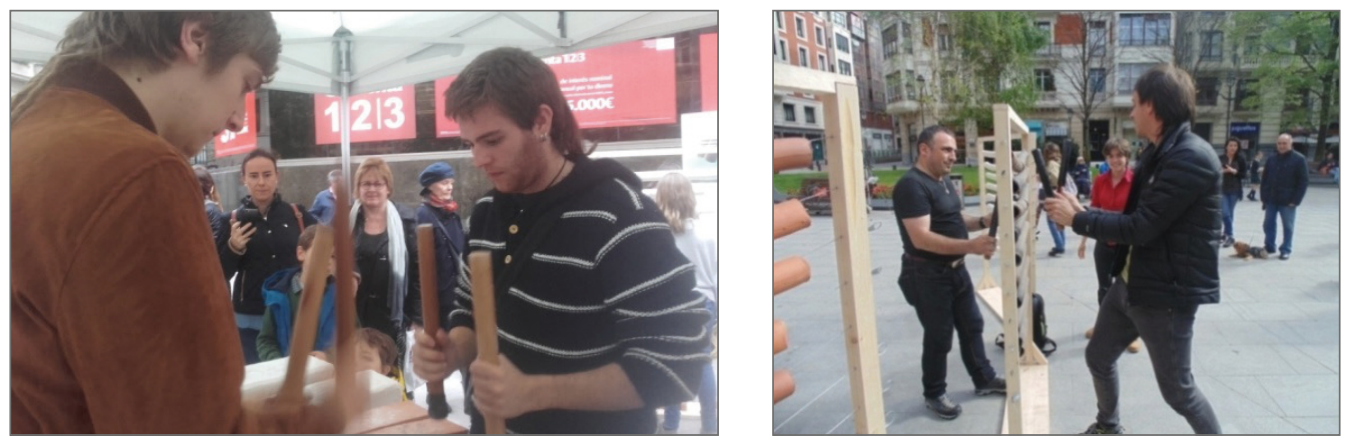

La txalaparta se convertía así en un instrumento integrador que provenía de una esencia baserritarra o de caserío que se trasladaba a grupos y colectivos provenientes de la ciudad, integrándose dentro de un ambiente urbano intercultural y con personas de diferentes edades. Una propuesta que traía consigo reflexiones ante su procedencia tanto cultural, antropológica y política, en la que se abandonaba el contexto exclusivamente vasco, que proponía la aceptación de otras subculturas sonoras, integrando a la vez a colectivos no favorecidos en el arte como pueden ser también personas con discapacidad.

La txalaparta cerámica, no fue solo la obra cuyos sonidos eran producto de esta forma de arte relacional. Integrándonos más afondo en la subcultura y tradición vasca también se realizaron piezas sonoras que recordaban a las toberas de la industria vasca. La obra compuesta por las toberas, más en relación con la experimentalidad del objeto, era mucho más atrac-

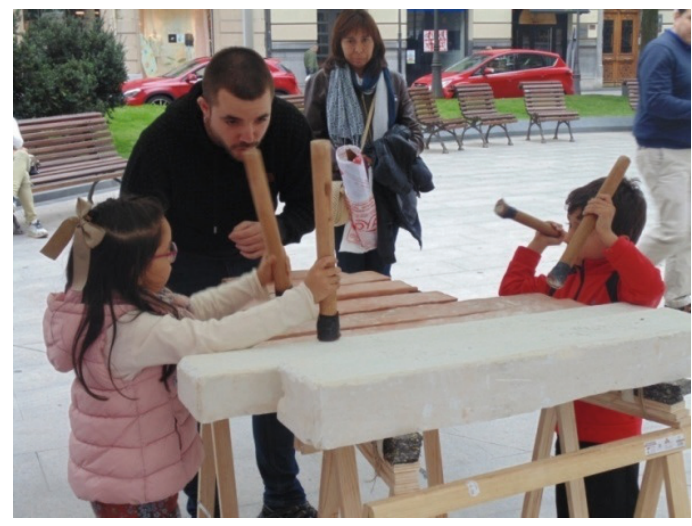


tiva para los jóvenes. Las personas adultas eran más temerosas de estropear la pieza escultórica, pero, aun así, su atracción por la puesta en escena del objeto tradicional conocido como txalaparta gustaba más.

\section{COHETE TOLEDO}

Teniendo en cuenta lo ocurrido en Bilbao Art District 2016, en 2018 tuve la oportunidad de trasladar el Ttakun Zeramikoa a Toledo y es que el simple hecho de crear una actividad participativa con un instrumento propio de la cultura vasca, en un territorio distinto a su lugar de procedencia dotaba a este proyecto de una experimentación e investigación acerca del comportamiento de un espectador que desconocía de este objeto, en otro lugar que nada tenía que ver con la cultura vasca.

A resumidas cuentas, preparé para Cohete Toledo una exhibición de txalapartas de diferentes soportes cerámicos y mejorados con respecto a Bilbao Art District. Escapamos de nuestras raíces vascas con la intención de incentivar nuevas experiencias en otros territorios.
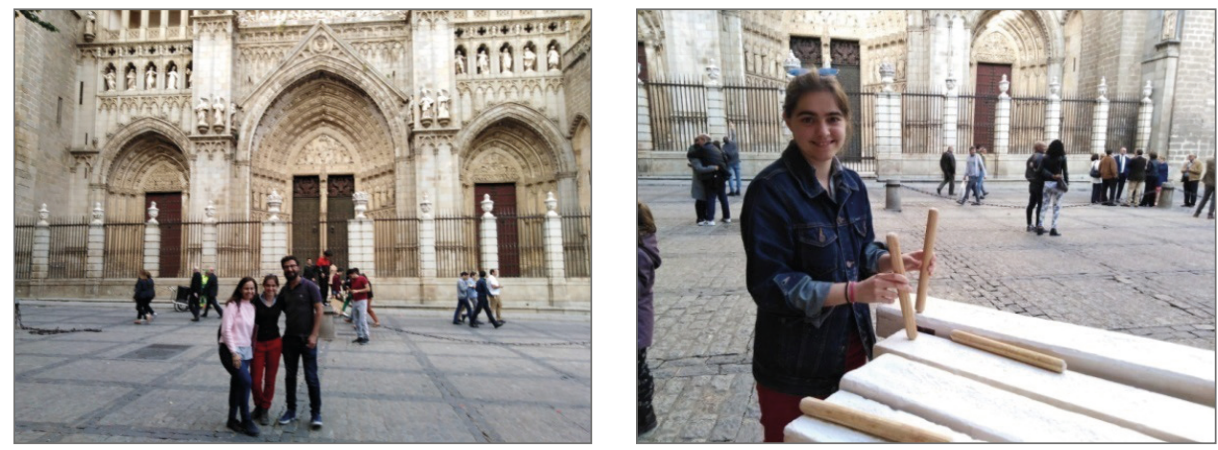

En cuanto a los aspectos formales de la obra, llevamos dos txalapartas desde Bilbao, una de barro y otra de escayola, ya que la escayola fue terriblemente atractiva tanto para músicos como desconocedores en la materia musical. Además, fue incluida una estructura similar de toberas de barro blanco sobre caballetes, un objeto mucho más sensible que las txalapartas, pero con un interés más artístico que musical. 
Al encontrarse fuera del País Vasco, darse a conocer era más que necesario para conocer esta iniciativa, por ello repartimos folletos en las calles de Toledo, en donde se explicaba el trabajo artístico. Al igual que en Bilbao Art District la puesta en escena comenzaba a la tarde sobre las 17:00 y las calles de Toledo ya estaban repletas de gente. La gran mayoría eran personas de Toledo y visitantes de otros países, y la gran cuestión era encontrar el modo de comunicarse con ellos.

Me di cuenta de que el simple ofrecimiento de los palos (makilak) con los que se tocaba la txalaparta y escuchar la resonancia musical de la misma dotaba de interés a esta obra y que la gente se acercaba sin miedo.

La posibilidad de llevar txalapartaris para este evento fue prácticamente imposible por lo que nos dejaba con más dificultades de exteriorizar nuestro proyecto. De todos modos, pudimos dar en Madrid con dos aficionados a la música que habían tenido relación con la cultura vasca y la fundamentación de este instrumento por lo que sabían tocarlo. Con buena iniciativa aceptaron a trasladarse a Toledo para intervenir como ayudantes para hacer partícipe a la

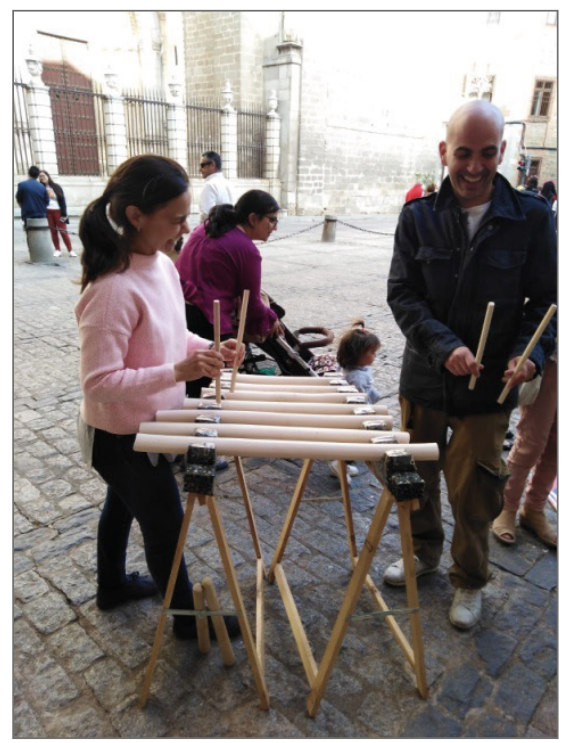
gente.

La inhibición de las personas para tocar era mucho menor y es que parecía ser que allí prácticamente nadie se conocía, estábamos de paso por Toledo al igual que la mayoría de los participantes que eran turistas y la aparición de un objeto tan peculiar desataba las necesidades de la integración ociosa del disfrute en la mentalidad de las personas.

Del mismo modo, colaborar con dos músicos aficionados dio la oportunidad de ver a este peculiar instrumento como un simple sonido urbano dejando de lado los ritmos clásicos de la txalaparta. Concluimos que la txalaparta fue bien golpeada por niños y adolescentes, con más ganas que las personas adultas al igual que en Bilbao Art District, aunque la presencia de un lugar en el que nadie se conocía ayudaba a un mayor interés por parte del participante por su afán al disfrute, dejando de lado ataduras de una música formalizada. 

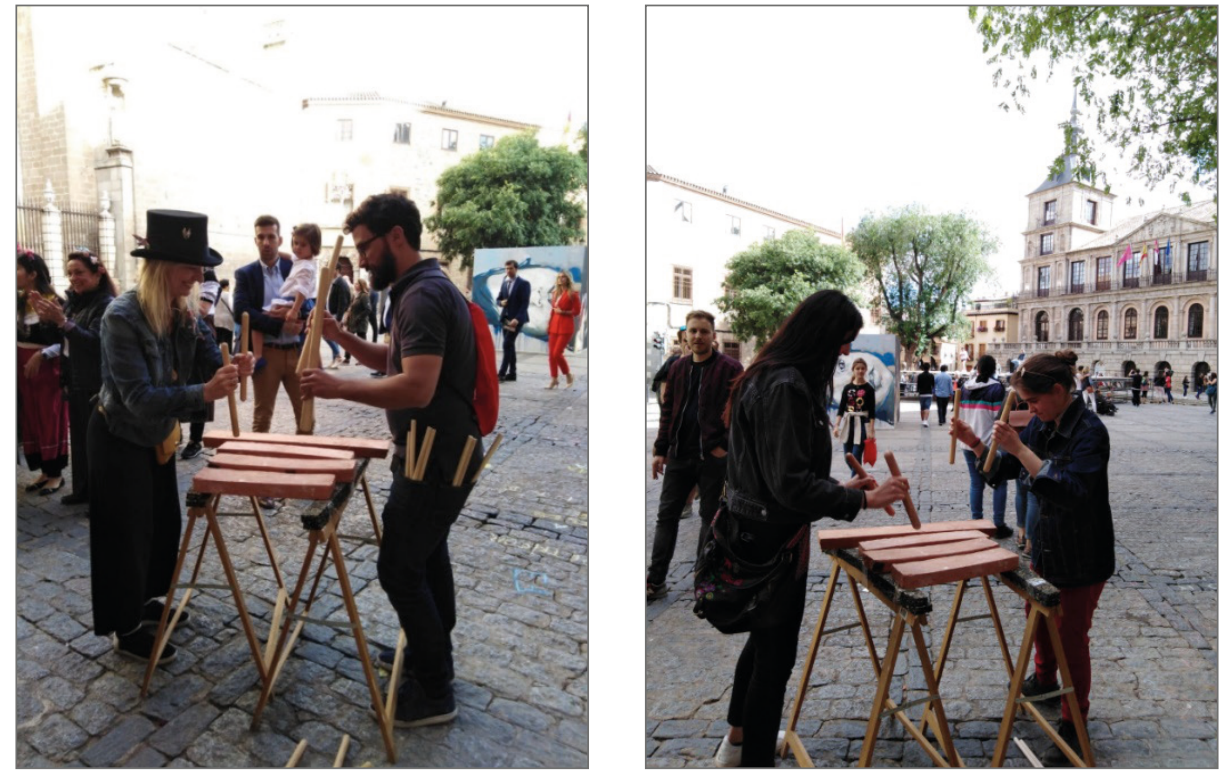

De algún modo este vínculo sonoro creaba un movimiento social en el que las culturas se interrelacionaban, expandiendo diferentes formas de entender los diferentes entornos del planeta, interrelacionando culturas y subculturas, aproximándose a una nueva visión complementaria entre continentes.

\section{CONCLUSIONES}

A medida que estos proyectos urbanos llegaban a su fin, concluí pensando que la perspectiva del arte todavía tenía mucho que indagar en cuanto a la adaptabilidad de los medios creativos en movimiento de arte relacional y sobre todo con una trayectoria sonora. A día de hoy, el artista no se relaciona tanto con el espectador. Puede que el problema de estas prácticas sea tratar a las personas de a pie como espectadores, ya que un espectador se trata de aquella persona que presencia un espectáculo, no una persona que toma parte de ello.

Puede que tratar a este nuevo espectador como urbanita, sea la salida a hacer al participante como un artista mas, ya que esta palabra según la Real Academia Española (RAE) significa "Persona que vive acomodada a los usos y cos- 
tumbres del lugar en el que esta o vive". Contemplamos este concepto como una iniciativa que mueve a las personas a indagar en aquellas propuestas urbanas de a pie que con el tiempo se convierten en ideas de subcultura que llegan a través de la voz, el diálogo y sobre todo de propuestas con sonoridad y movimiento en el espacio tiempo.
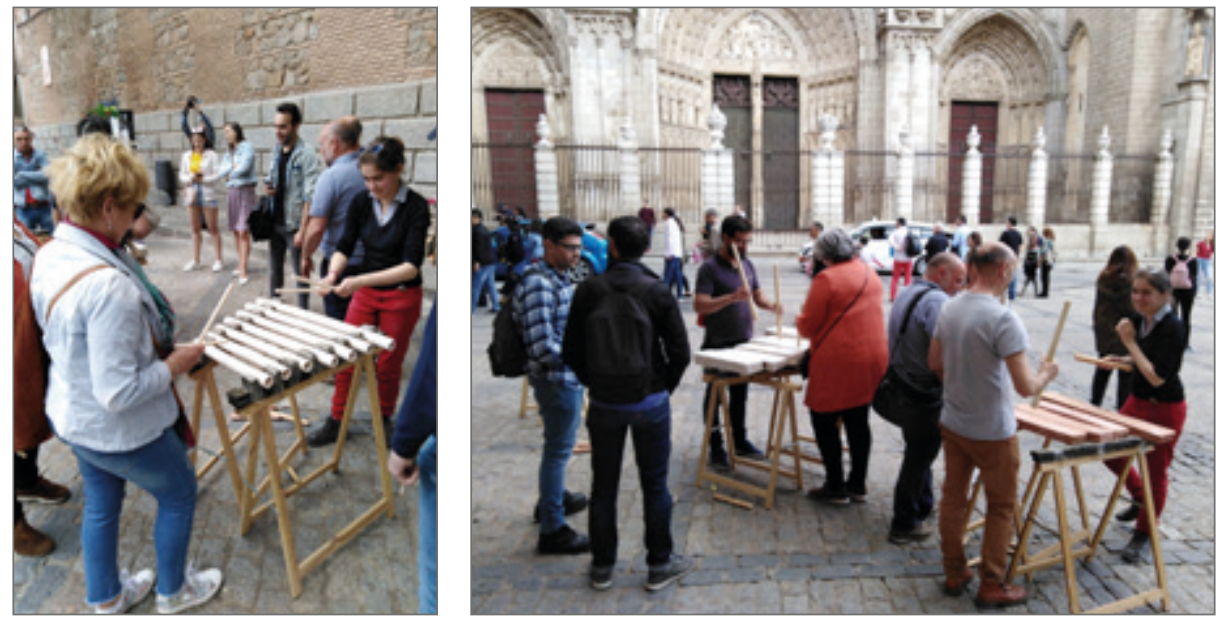

Sea el lugar que sea, sea la propuesta subcultural que sea, sea la interpretación personal o colectiva que sea, siempre llega trasmitiendo unos ideales que se trasladan del yo al tú y viceversa, en donde el trabajo de la artista sonora no debe sólo ceñirse al momento de la creación, sino también al estudio de aquello que sucede en las intervenciones callejeras, pues la conducta de aquellos urbanitas dará paso a una investigación que relaciona diferentes disciplinas académicas y que ayuda a crear futuras obras artísticas y sonoras, relacionando así una creatividad personalizada con las sociedades. Indagamos así en el estudio de la conducta humana en su mentalidad cultural y trasmitiendo así diferentes derivas artísticas que nutran a los individuos.

El Ttakun Zeramikoa hoy día es el comienzo de una investigación sobre la conducta humana a través de los sentidos en el arte y que ha dado pie a otros proyectos sensoriales en la que intervienen ideas, tales como el juego musical en comunicación con el urbanita. Los trabajos de Allan Kaprow y John Dewey sobre las actividades de la vida cotidiana recuerdan que tras el juego y la libre interacción puede surgir el arte (Kelley 2004) de manera espontánea. La facilitación de este tipo de iniciativas me ha llevado a través de mi actual tesis doctoral a explorar la interacción entre artistas y públicos con diversidad 
sensorial para crear nuevos paradigmas de adaptabilidad y entrelazamiento de lenguajes entre personas.

\section{Referencias bibliográficas}

Aita Donostia [José Gonzalo Zulaika y Arregi]. 1948. Notas acerca de las canciones de trabajo en el País Vasco. Barcelona

— . 1983. "Instrumentos musicales populares vascos". En Obras completas del P. Donostia, t. II., 257-309. Bilbao: La Gran Enciclopedia Vasca

Arze, Joxe Anton. 1969. Isuritze-tik Tolosan barru. Usurbil: Harzabal

Beltran Argiñena, Juan Mari. 1988. "Txalaparta". Cuadernos de Etnologia y Etnografia de Navarra 52: 419-39

— . 2001. "Lan erritmoetatik musikara". Jentilbaratz 7: 119-55

- . 2004. Txalaparta eta beste aldaera zaharrak: Lan erritmoetatik musikara [La txalaparta, antecedentes y variantes: De los ritmos de trabajo a la música]. Oiartzun: Herri Musikaren Txokoa

Diaz Perez, Ernesto. 1966. "La txalaparta puede ser el pilar de la música moderna vasca". Txistulari 47

Escribano del Moral, María. 2004. "La txalaparta a través del tiempo: Un análisis etnomusicológico". Sukil 4: 113-25

Euba Ugarte, Argibel. 2016. Basker: Documentales suecos sobre cultura vasca en la década de 1960. Bilbao: Universidad del País Vasco

Gompertz, Will. 2013. ¿Qué estás mirando? 150 años de arte moderno en un abrir y cerrar de ojos. Traducción de Federico Corriente Basús. Madrid: Taurus

Hurtado Mendieta, Enrike. 2015. "Txalaparta y vanguardia, ruido y música”. AusArt 3 (2): 58-68. https://doi: 10.1387/ausart.15934

Kelley, Jeff. 2004. Childsplay: The art of Allan Kaprow. With a foreword by David Antin. Berckeley CA: University of California

Krauss, Rosalind E. (1979) 2002. "La escultura en el campo expandido". En La posmodernidad, Jean Baudrillard et al.; selección y prólogo de Hal Foster; traducción, Jordi Fibla, 59-74. Barcelona: Kairós 